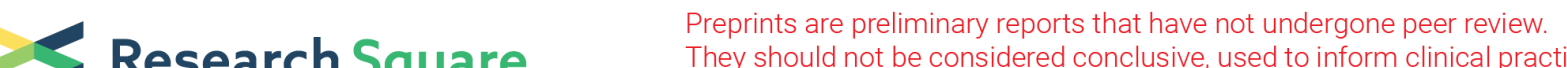 $\begin{array}{ll}\text { Research Square } & \text { They should not be considered conclusive, used to inform clinical practice, } \\ \text { or referenced by the media as validated information. }\end{array}$
}

\section{Iranian Primary Healthcare System's Response to Pandemic Covid- 19 Using Healthcare Incident Command System}

\author{
Arezoo Yari \\ Kurdistan University of Medica Sciences \\ Homa Yousefi-Khoshsabeghe \\ Tehran University of Medical Sciences \\ Yadolah Zarezadeh \\ Kurdistan University of Medica Sciences \\ Majid Amraei \\ Ministry of Health and Medical Education \\ Mohsen Soufi Boubakran \\ Urmia University \\ Mohamad Esmaeil Motlagh ( $\sim$ Dr.motlagh.ms@gmail.com) \\ University of Medical Sciences
}

\section{Research Article}

Keywords: Primary Healthcare, Healthcare Incident Command System, Covid-19, District Health Networks

Posted Date: March 17th, 2021

DOI: https://doi.org/10.21203/rs.3.rs-313718/v1

License: (c) (i) This work is licensed under a Creative Commons Attribution 4.0 International License.

Read Full License 


\section{Abstract}

Background: The healthcare incident command system (HICS) is a potent disaster management tool in healthcare systems. The present study aimed to evaluate the effects of HICS on the district health networks (DHNs) covered by provincial Medical Universities (PMU) in terms of the management and commanding of the corona crisis in Iran.

Methods: This cross-sectional research was performed in June 2020 in Iran. Data were collected using the HICS assessment tool by trained crisis management experts in the DHNs. In addition, we investigated the effects of the HICS use on the management and commanding of the corona crisis. Furthermore, the effects of the HICS use were evaluated on two groups of DHNs with active HICS and DHNs with inactive or no HICS.

Results: The total mean score of the corona incident command and management was $78.79 \pm 11.90$ (range: 20-100) in all the DHNs. The DHNs had the highest scores in the dimensions of organizational support and coordination and the lowest score in the dimension of support and planning. Significant differences were observed between the DHNs with active HICS and DHNs with inactive or no HICS in terms of the mean scores of incident management and command and its dimensions.

Conclusions: According to the results, the HICS use had a positive impact on the improvement of incident management and command and all of its dimensions. Therefore, the HICS could be used in primary healthcare for the systematic and proper management of infectious disease crises and increasing their efficiency in response to these phenomena.

\section{Background}

The coronavirus pandemic is a mass casualty incident $(\mathrm{MCl})$, which requires $\mathrm{MCl}$ disaster management based on the four main incident management stages of mitigation, planning, response, and recovery (1). Spreading quickly across the world in 2019, the coronavirus disease (COVID-19) was identified as a global pandemic on March 11th, 2020 (2). The disease has been an unprecedented challenge for health systems (3). An important issue in this regard is the increased number of the patients and implementation of system-level operational compatibility (4). Meanwhile, the disease has significantly impacted the health systems of low- and middle-income countries (5). Iran confirmed the spread of corona in the country on February 19th, 2019, and all the provinces reported cases of the corona disease up to March $5^{\text {th, }} 2020$ due to the rapid spread of the virus (6). Furthermore, an increase was also reported in the load of the disease and number of the corona-related deaths in Iran due to concomitance with the international sanctions against this country (2), as well as the shortage of medical, pharmaceutical, and laboratory equipment (7).

The corona pandemic showed that the world is constantly affected by outbreaks of various diseases despite the advances in medical sciences (8). Medical sciences have failed to manage this crisis without the principles of crisis management. Emergency management is an inherent element of health systems 
(9), and emergency planning is a key responsibility of health systems (10). Based on global experiences, the healthcare incident command system (HICS) is a valuable incident management tool, which plays a pivotal role in increasing the quality of primary healthcare' services (11). According to the crisis management cycle, the HICS activation in the phase of response to the corona crisis is essential to the practical organization of the affected areas by the viral infection (4). The structure operates by using a logical and integrated management structure, describing responsibilities, developing clear reporting channels, and applying a common and simple terminology system for the further coordination of the institutions involved in unexpected events $(13,14)$. Moreover, the method could be exploited by Public health care centers to enhance emergency planning and response in disasters and emergencies regardless of their size or ability in patient care (15). HICS consists of five operational systems, including command, planning, operation, logistics, and finance/administration (16).

Although the corona pandemic is regarded as a health emergency, it cannot be combated only through normal medical and preventive measures. In fact, the effective management of the disease requires health interventions, through which public health surveillance systems are realized as the most essential components of contagious disease management in emergencies are the presence of a healthcare system and rapid introduction of proper control measures $(17,18)$. The establishment of a surveillance system in emergencies, incidents or disasters is a complicated process and requires various resources, such as human resources and specific administrative facilities and equipment (19).

The HICS provides the operational coordination required by an organization to respond to disease outbreaks (4). In addition, the organization defines the roles and responsibilities of individuals, organizational response functions, power lines, and communication and management practices (16). Today, the HICS is widely used by healthcare systems (3). Iran has a large network of primary health care (PHC), which provides healthcare services to the rural and urban areas of the country (20). The Ministry of Health and Medical Education (MOHME) has necessitated that all health systems use this infrastructure since 2011 based on the national disaster response framework (21). With the outbreak of the coronavirus in Iran, the authorities officially announced the activation of this framework in the healthcare system on all levels.

In response to the corona threat, the UW Medicine Systems in the health system of the United States used the HICS instructions to collect organizational resources (3). However, limited research has been focused on the implementation and evaluation of this framework despite its long-term use in the world $(11,22)$; in other words, no comprehensive research has investigated the positive and negative impacts of this system (22). Overlooking some of the quality-related aspects of the issue might be due to the importance of establishing the HICS for emergencies (11).

Given the outbreak of the coronavirus in Iran and history of using the HICS in the primary healthcare system of the country, the present study aimed to evaluate the effects of using the HICS in the district health networks (DHNs) covered by provincial medical universities (PMUs). 


\section{Methods}

This cross-sectional study was conducted in the DHNs covered by the PMUs in Iran in June 2020. In total, 60 out of 62 DHNs were participated in this research. In Iran, public health care (PHC) is based on the $\mathrm{DHN}$; in other words, every area has a regional DHN, which is an organization constituting of District Health Centers (DHC), rural health centers, urban health centers, health houses, and a health posts that provide healthcare services to all parts of the region. On the other hand, the network is considered to be a sub-organization of the PMU, Each PMU covering one or more regions and monitoring PHC provision in the province. Notably, some provinces have more than one PMU and the regions of the province been divided between them. (23) (Fig. 1).

In the Iranian primary healthcare system, the HICS has a command group and four section including planning, operation, logistics, and finance/administration. The command group encompasses the five situations of incident commander, public information officer, liaison officer, safety officer, and security officer (24) (Fig. 2). In the present study, we applied the HICS evaluation tool to assess the HICS in Iranian DHNs during the coronavirus crisis. The tool consisted of 50 items to assess incident management in the four dimensions of organizational support, the implementation process of incident management, resource and equipment management, and human resource management. The executive process of incident management is performed through coordination, communication, and operations. The validity and reliability of the tool have been reported to be acceptable for the Iranian population (25).

In the present study, the total scores of incident command and its dimensions were determined by calculating the score of each dimension separately and weighting the score based on the number of the items in each dimension. Following that, the scores of all the dimensions were summed up and divided by the total number of the items to calculate the total score of incident command. The total scores of incident command and its dimensions were determined within the range of 20-100. By dividing the total score and scores of the dimensions, the scores were classified as low, medium, and high; the scores below the first quarter were defined as low, the scores within the quarters 1-3 were considered medium, and the scores above the third quarter were defined as high.

All DHNs in Iran have Disaster Risk Management Offices (DRMO) with disaster risk management experts who are experienced in attending the training courses of disaster management and HICS. In each DHN selected in the current research, data were collected by the disaster risk management expert of the DHN. Information was collected from the DHN executives or key members of the Corona Crisis Committee, each of whom was partly responsible for the corona crisis management. For instance, the questions regarding the human resources were asked of the human resources department manager, and the questions regarding the equipment and resources were asked of the head of the equipment and resources department. The surveyors were trained on the collection of data online and via virtual sessions and allowed to contact the research team in case of ambiguities. After the necessary training and providing explanations about the objectives and methodology of the research and ethical considerations to ensure the strength of the collected data, the research team meticulously monitored the performance of the 
surveyors. After data collection, post-performance control, assessment, and statistical control of the tools were performed as well.

In the present study, the Iranian DHNs were divided into two groups; the first group had an active HICS, and the second group had no HICS or had an inactive HICS. Both groups completed the questionnaire of the corona incident management status, and the results were compared. Finally, the impact of the HICS activation on the improvement of the response rate to the corona crisis in the country was assessed by comparing various aspects of incident management in the two DHN groups (Fig. 1).

Data analysis was performed in SPSS version 22 using descriptive indexes (percentage, mean, and standard deviation) and t-test.

\section{Results}

In the present study, $98 \%$ of the universities cooperated with the researchers. In total, $68.3 \%$ of the participating universities $(n=60)$ had activated their HICS, while $31.7 \%$ had no HICS or active HICS. The total mean score of the corona incident command and management based on various dimensions of the framework was $78.79 \pm 11.90$ (score range: $20-100$ ) in all the Iranian DHNs. Based on the score classification, $25 \%$ of the DHNs obtained high scores, while $50 \%$ and $25 \%$ obtained medium and low scores, respectively. The findings also indicated that the DHNs had the highest score in terms of organizational support and coordination and the lowest score in terms of logistic and planning (Table 1).

Table 1

Healthcare Incident Command level based on the HICS constructs at time of COVID-19 in the Iranian DHNs $(n=60)$

\begin{tabular}{|lllll|}
\hline $\begin{array}{l}\text { Healthcare Incident Command system } \\
\text { constructs }\end{array}$ & $\begin{array}{l}\text { Low } \\
\mathbf{n}(\%)\end{array}$ & $\begin{array}{l}\text { Average } \\
\mathbf{n}(\%)\end{array}$ & $\begin{array}{l}\text { High } \\
\mathbf{n}(\%)\end{array}$ & $\begin{array}{l}\text { Total Score } \\
\text { Mean } \pm \text { SD }\end{array}$ \\
\hline Total Incident Management and Command & $15(25.0)$ & $30(50.0)$ & $15(25.0)$ & $78.79 \pm 11.90$ \\
\hline Organizational support & $26(43.3)$ & $10(16.7)$ & $24(40.0)$ & $84.33 \pm 11.63$ \\
\hline Operational & $12(20.0)$ & $31(51.7)$ & $17(28.3)$ & $75.77 \pm 12.17$ \\
\hline Coordination & $16(26.7)$ & $30(50.0)$ & $14(23.3)$ & $82.66 \pm 14.54$ \\
\hline Communication & $17(28.3)$ & $28(46.7)$ & $15(25.0)$ & $79.86 \pm 13.97$ \\
\hline Planning & $17(28.3)$ & $30(50.0)$ & $13(21.7)$ & $73.11 \pm 16.14$ \\
\hline Logistic & $15(25.0)$ & $35(58.3)$ & $10(16.7)$ & $69.13 \pm 17.24$ \\
\hline Human resource management & $30(50.0)$ & $16(26.7)$ & $14(23.3)$ & $81.91 \pm 14.73$ \\
\hline
\end{tabular}


Based on the classification of the incident management and command and the associated dimensions, the obtained results showed that $34.2 \%$ of the DHNs with active HICS commanded and managed the corona crisis at a high level, while $73.7 \%$ of the DHNs with no active HICS commanded and managed the corona crisis at a low level. In addition, the DHNs with active HICS achieved higher scores in the HICS dimensions compared to the DHNs with inactive HICS, so that none of the DHNs with inactive HICS could be considered high-level in terms of planning, logistics, and human resource management (Table 2).

Table 2

Comparison of DHNs with an active HICS and without active HICS or no HICS according to HICS' constructs at time of COVID-19 in Iran $(n=60)$

\begin{tabular}{|c|c|c|c|c|c|c|}
\hline \multirow[t]{2}{*}{$\begin{array}{l}\text { Healthcare Incident Command } \\
\text { system constructs }\end{array}$} & \multicolumn{3}{|c|}{$\begin{array}{l}\text { DHNs with an active HICS } \\
(n=41)\end{array}$} & \multicolumn{3}{|c|}{$\begin{array}{l}\text { DHNs without active HICS or } \\
\text { no HICS } \\
(n=19)\end{array}$} \\
\hline & $\begin{array}{l}\text { Low, } \\
\text { n (\%) }\end{array}$ & $\begin{array}{l}\text { Average } \\
\mathrm{n}(\%)\end{array}$ & $\begin{array}{l}\text { High, } \\
\text { n (\%) }\end{array}$ & $\begin{array}{l}\text { Low, } \\
\text { n (\%) }\end{array}$ & $\begin{array}{l}\text { Average, } \\
\mathrm{n}(\%)\end{array}$ & $\begin{array}{l}\text { High, } \\
\text { n (\%) }\end{array}$ \\
\hline $\begin{array}{l}\text { Total Incident Management } \\
\text { and Command }\end{array}$ & $5(12.2)$ & $22(53.7)$ & $14(34.1)$ & $10(52.6)$ & $8(42.1)$ & $1(5.3)$ \\
\hline Organizational support & 12(29.3) & $7(17.1)$ & $22(53.7)$ & 14(73.7) & $3(15.8)$ & $2(10.5)$ \\
\hline Operational & $6(14.6)$ & $20(48.8)$ & 15(36.6) & $6(31.6)$ & 11(57.9) & $2(10.5)$ \\
\hline Coordination & $5(12.2)$ & $23(56.1)$ & 13(31.7) & 11(57.9) & $7(36.8)$ & $1(5.3)$ \\
\hline Communication & $10(24.4)$ & $19(46.3)$ & $12(29.3)$ & $7(36.8)$ & $9(47.4)$ & $3(15.8)$ \\
\hline Planning & $7(17.1)$ & $21(51.2)$ & 13(31.7) & $10(52.6)$ & $9(47.4)$ & $0(0.0)$ \\
\hline Logistic & $7(17.1)$ & $24(58.5)$ & $10(24.4)$ & $8(42.1)$ & $11(57.9)$ & $0(0.0)$ \\
\hline Human resource management & $14(34.1)$ & 13(31.7) & $14(34.1)$ & $16(84.2)$ & $3(15.8)$ & $0(0.0)$ \\
\hline
\end{tabular}

The analytical results of the present study indicated that the mean scores of command and incident management and the associated dimensions significantly differed between the DHNs with an activated HICS and those with an inactive HICS (Table 3). 
Table 3

Comparison of mean scores of HICS constructs at time of COVID-19 in the Iranian DHNs $(n=60)$

\begin{tabular}{|lllll|}
\hline $\begin{array}{l}\text { Healthcare Incident Command } \\
\text { system constructs }\end{array}$ & $\begin{array}{l}\text { DHNs with an } \\
\text { active HICS } \\
(\mathbf{n}=\mathbf{4 1})\end{array}$ & $\begin{array}{l}\text { DHNs without active } \\
\text { HICS or no HICS } \\
\text { Mean } \pm \text { SD }\end{array}$ & $\begin{array}{l}\mathbf{n}=\mathbf{1 9}) \\
\text { Mean } \pm \text { SD }\end{array}$ & $\begin{array}{l}\mathbf{P} \\
\text { value }\end{array}$ \\
\hline Total Incident Command & $83.02 \pm 9.35$ & $69.67 \pm 11.88$ & 4.710 & 0.000 \\
\hline Organizational support & $87.80 \pm 9.98$ & $76.84 \pm 11.62$ & 3.753 & 0.000 \\
\hline Operational & $78.69 \pm 11.47$ & $69.47 \pm 11.50$ & 2.895 & 0.005 \\
\hline Coordination & $87.51 \pm 12.03$ & $72.21 \pm 14.21$ & 4.322 & 0.000 \\
\hline Communication & $83.02 \pm 12.28$ & $73.05 \pm 15.25$ & 2.706 & 0.009 \\
\hline Planning & $79.67 \pm 12.64$ & $58.94 \pm 13.74$ & 5.747 & 0.000 \\
\hline Logistic & $74.82 \pm 13.97$ & $56.84 \pm 17.51$ & 4.274 & 0.000 \\
\hline Human resource management & $87.43 \pm 10.06$ & $70.00 \pm 16.32$ & 5.085 & 0.000 \\
\hline
\end{tabular}

\section{Discussion}

Several factors affect corona crisis management in health systems. However, few studies regarding the coronavirus have been focused on the management of the crisis based on disaster management principles. The present study aimed to evaluate various aspects of corona management and command in two groups of the DHNs covered by the PMUs of Iran. A key strength of our study was the evaluation of various dimensions of corona incident command based on a global algorithm, which encompassed all the aspects of incident command and management in an emergency.

According to the current research, the DHNs with an active HICS system had more favorable organizational support compared to the DHNs without an HICS or those that had not activated the HICS. Overall, an HICS has multiple functional areas with specific purposes. The goals of each region are hierarchically in line with the basic goals of the system and programs set by the upper echelons, so that the presence of HICS functional areas could ultimately enable the organization to achieve multiple goals (26), which in turn improved organizational support.

The value of the HICS system in the reduction of organizational differences has been an issue raised in this regard, especially in large-scaled events (27). This could be due to the fact that the mere existence of an HICS does not guarantee organizational success and may not enhance organizational support. In fact, the strong commitment of organizational executive leaders, culture of organizational promptness, budget to support planning, training, and practice significantly impact executive commitment and the success of HICS, which in turn promote organizational support (22). Furthermore, determining the organizational 
hierarchy of the HICS structure based on application requirements rather than the titles and positions of individuals plays a crucial role in organizational success (28).

The HICS is an accurate, broad-spectrum management system in public health environments to define operational specifications, interactive management components, and incident management structures (26). This framework is also a standard system for disaster response (29), as well as a standard management system (30). Nevertheless, Stephen S. Morse has claimed that many health organizations are not comfortable with the use of this system (31). In another study, Burkle F. M. et al. discussed the application of the framework in health-related disasters on a large scale, especially in an epidemic (32). In this regard, our findings indicated that the executive operation score of the DHNs with an active HICS was significantly higher compared to the DHNs with an inactive HICS or no HICS during the corona crisis. In fact, the HICS has been observed to improve organizational operations during disasters through prioritized operation checklists, identifying positions, and teamwork (14). In addition, the framework is considered proper for complicated and multidisciplinary operations (33), so that the failure of one component of the HICS would not lead to the failure of the other components (34). The efficiency of the system and its operations could enhance by measures such as promoting the culture of familiarity with the HICS (12), familiarity with the organizational structure of the HICS (35), and the scientific and practical training of staff regarding the framework and implementation of training (36). The HICS provides a standard response format and increases coordination since it could be recognized by the organizations and various sectors that are responsible for incident management, thereby affecting the response rate (14).

According to the results of the present study, the HICS could improve the coordination status in the corona crisis management, and the coordination score of the DHNs with an active HICS in the coronavirus pandemic significantly differed with the DHNs with an inactive or no HICS. In fact, the framework provides the opportunity for the coordinated response to emergencies $(33,34,37,38)$, as well as the multidisciplinary coordination for response to public health threats (33). In addition, the system creates unity in severe crises by enabling the use of reciprocal efforts $(27,39)$.

In the current research, the DHNs with an active HICS had better communications in the corona crisis management, and the difference between the DHN groups was considered significant in this regard. In general, the HICS is a communication system (40), which enables the communication and sharing of resources between health institutions and organizations (37). The framework also promotes administrative communications (22) through establishing clear inter-organizational associations (38) and preventing unnecessary communications (41), while also facilitating communications between hospitals, medical emergencies, and other response systems $(40,42)$ and foreign organizations (43). Although this system is not an actual disaster plan, it acts as a guide to the proper organizational management of an emergency $(37,40)$, thereby increasing the ability to retrieve scheduled and unplanned events (44) and remarkably facilitating responding, planning, decision-making, and documentation (13). 
In the present study, the PMUs with an active HICS had better planning, while none of the DHNs with an inactive or no HICS had a high planning score. Among the studied dimensions, the lowest corona crisis command score in the DHNs in Iran belonged to the planning dimension. Considering that the HICS improves planning, it is essential to assess its activation and correction in organizational planning prior to an incident or disaster (22) and cluster the obtained data based on the actual response stage method in order to improve the efficiency of the HICS structures and activities in the planning stage (32). Moreover, the framework could help eliminate the lack of the executive commitment of the system in the planning department (22).

According to the results of the present study, the weakest incident command dimension in the Iranian DHNs was the logistics dimension. In other words, the lowest score was obtained in this dimension, which might be due to the international sanctions against Iran during the current pandemic (2). Considering this issue, the elimination of the financial barriers of the health system and financially supporting the establishment of the HICS improve the efficiency of the framework (45). Despite the international sanctions, the DHNs with an active HICS had extremely better performance in the logistics field in the current research. On the other hand, the DHNs with an inactive HICS or no HICS had improper performance and could not obtain high scores in any of the dimensions. Therefore, it could be concluded that the system is able to reduce the loads of logistic problems during crises by exploiting all the resources for problem-solving (28), supply needs, resources, and equipment (46), thereby providing the health facilities required for emergency management (30).

According to the results of the present study, the human resource management of the DHNs with an active HICS was significantly better than the DHNs with an inactive or no HICS. In addition, none of the DHNs with an inactive or no HICS obtained a favorable score in this dimension. By providing services in the shortest possible time (12), identifying the areas for expanding services during patient overload periods (46), preventing rework (38), and using human resources regularly (39), the HICS encourages individuals to take on the necessary responsibilities in a timely manner (45), which in turn results in effective human resource management, as well as adequate and efficient human resources (38).

\section{Conclusion}

Considering the efficiency of the HICS in the management and command of the coronavirus crisis and the aspects of organizational support, executive operations, coordination, communication, planning, logistics, and human resource management, it is recommended that the HICS be established in primary healthcare systems in the preparation phase and prior to biological crises and public health epidemics in order to identify the challenges and complications in organizational planning and assess the related practices and maneuvers, while also using the principles in the phase of response to epidemics such as corona. The use of this system leads to the systematic management and proper command of infectious disease crises, thereby increasing the efficiency of health systems in response to these crises.

\section{Abbreviations}


HICS: healthcare incident command system; DHNs: district health networks; PMU: provincial Medical Universities; MOHME: Ministry of Health and Medical Education; MCl: mass casualty incident; PHC: primary health care; DHC: District Health Centers; DRMO: Disaster Risk Management Offices.

\section{Declarations}

\section{Ethics approval and informed consent to participate}

This study has acquired the approval of Kurdistan University of Medical Sciences' Institutional Review Board (IRB). The IRB follows the stipulated clauses of the Helsinki Declaration. Ethics Committee of Kurdistan University of Medical Sciences approved this study and Ethical Approval Number “IR.MUK.REC.1399.020” was obtained. This committee follows the required principles of the Helsinki Declaration. Informed consent was obtained and ethical principles such as confidentiality and the right of withdrawal at any time was explained to the participants. The participants in this study were previously informed about the characteristics of the study. They were all asked to participate in the study and to provide written consent to confirm the participation in the study.

\section{Consent for publication}

Not applicable

\section{Availability of data and materials}

The datasets used and/or analyzed during the current study are available from the corresponding author on reasonable request.

\section{Competing interests}

The authors declare that they have no competing interests.

\section{Funding}

This study (no: 1399/2/21-14/7935) was funded by the Disaster Risk Management Offices at Ministry of Health and Medical Education in IRAN.

\section{Authors' contributions}

AY, MEM and HYK researched the background for the project and was the primary writer of the manuscript with the guidance of MEM, YZ and MSB. AY, MA, MSB analyzed and interpreted the data. To ready this manuscript for publication $Y Z, A Y, M A$ and $M E M$ edited the manuscript. All authors read and approved the final manuscript.

\section{Acknowledgements}


This study was carried out with the support of the Kurdistan University of Medical Sciences and funded by Disaster Risk Management Office in Ministry of Health. The authors appreciate the executive and financial support of the Kurdistan University of Medical Sciences and Disaster Risk Management Office in Ministry of Health respectively. Moreover, the authors would like to thank all participants of the study who gave us their precious time.

\section{References}

1. Coccolini F, Sartelli M, Kluger Y, Pikoulis E, Karamagioli E, Moore EE, Biffl WL, Peitzman A, Hecker A, Chirica M, Damaskos D. COVID-19 the showdown for mass casualty preparedness and management: the Cassandra Syndrome. World Journal of Emergency Surgery. 2020 Dec;15:1-6.

2. Takian A, Raoofi A, Kazempour-Ardebili S. COVID-19 battle during the toughest sanctions against Iran. Lancet (London, England). 2020 Mar 28;395(10229):1035.

3. Grange ES, Neil EJ, Stoffel M, Singh AP, Tseng E, Resco-Summers K, Fellner BJ, Lynch JB, Mathias PC, Mauritz-Miller K, Sutton PR. Responding to COVID-19: the UW medicine information technology services experience. Applied clinical informatics. 2020 Mar;11(2):265.

4. Tosh PK, Bucks CM, O'Horo JC, DeMartino ES, Johnson JM, Callies Jr BI. Elements of an Effective Incident Command Center. InMayo Clinic Proceedings 2020 Sep 1 (Vol. 95, No. 9, pp. S3-S7). Elsevier.

5. Rutter $\mathrm{H}$, Horton R, Marteau TM. The Lancet-Chatham House Commission on improving population health post COVID-19. The Lancet. 2020 Jul 18;396(10245):152-3.

6. Raoofi, A., Takian, A., Sari, A.A., Olyaeemanesh, A., Haghighi, H. and Aarabi, M., 2020. COVID-19 pandemic and comparative health policy learning in Iran. Archives of Iranian Medicine, 23(4), pp.220234.

7. Jahanshahi, A.A., Dinani, M.M., Madavani, A.N., Li, J. and Zhang, S.X., 2020. The distress of Iranian adults during the Covid-19 pandemic-More distressed than the Chinese and with different predictors. Brain, behavior, and immunity.

8. Ciottone GR. Introduction to disaster medicine in Ciottone GR, Biddinger PD, Darling RG, Fares S, Keim ME, Molloy MS, Suner S, editors. Ciottone's disaster medicine. Second Edition. Elsevier Health Sciences 2015; pp:2-5.

9. Murota T, Kato A, Okumura T. Emergency management for information systems in public health a case study of the 2009 pandemic-flu response in japan. In2010 8th IEEE International Conference on Pervasive Computing and Communications Workshops (PERCOM Workshops) 2010 Mar 29 (pp. 394-399). IEEE. https://doi.org/10.1109/PERCOMW.2010.5470637

10. Boyd A, Chambers N, French S, King R, Shaw D, Whitehead AS. A scoping study of emergency planning and management in health care: What further research is needed. Final report. NIHR Health Services and Delivery Research programme. 2012.

11. Shooshtari S, Tofighi S, Abbasi S. Benefits, barriers, and limitations on the use of Hospital Incident Command System. Journal of Research in Medical Sciences. 2017;22. 
12. AkhavanMoghaddam J., Adibnejad S., Mousavi-Naaeni S. M. Introducing Hospital Emergency Incident Command System (HEICS) and HEICS Implementation in Iran Hospitals. J Mil Med. 2005; 7 (2) :167-175.(Persian)

13. Molino Sr LN. Emergency incident management systems: Fundamentals and applications: John Wiley \& Sons; 2006.

14. Authority CEMS, Ballay C. Hospital Incident Command System Guidebook: California Emergency Medical Services Authority; 2014.

15. Centers for Disease Control and Prevention (CDC. Early warning disease surveillance after a flood emergency-Pakistan, 2010. MMWR. Morbidity and mortality weekly report. 2012 Dec 14;61(49):1002.

16. Djalali A, Castren M, Hosseinijenab V, Khatib M, Ohlen G, Kurland L. Hospital Incident Command System (HICS) performance in Iran; decision making during disasters. Scandinavian journal of trauma, resuscitation and emergency medicine. 2012 Dec;20(1):1-7.

17. Yan GU, Su XM. Mobile device-based reporting system for Sichuan earthquake-affected areas infectious disease reporting in China. Biomedical and Environmental Sciences. 2012 Dec 1;25(6):724-9. https://doi.org/10.3967/0895-3988.2012.06.016

18. Tohma K, Suzuki A, Otani K, Okamoto M, Nukiwa N, Kamigaki T, Kawamura K, Nakagawa H, Oshitani $\mathrm{H}$. Monitoring of influenza viruses in the aftermath of the Great East Japan earthquake. Japanese journal of infectious diseases. 2012;65(6):542-4. DOI: 7883/yoken.65.542

19. Freedman AM, Mindlin M, Morley C, Griffin M, Wooten W, Miner K. Addressing the gap between public health emergency planning and incident response: Lessons learned from the $2009 \mathrm{H} 1 \mathrm{~N} 1$ outbreak in San Diego County. Disaster Health. 2013;1(1):13-20.

20. Ardalan A. Evidence-Based Integration of Disaster Risk Management to Primary Health Care, the Case of I.R.Iran. UNISDR Scientific and Technical Advisory Group Case Studies.2015.http://www.preventionweb.net/files/workspace/7935_ardalanirancasestudy.pdf.

21. Ardalan a, Moradian MJ, Saberinia A, et al. I.R.Iran National Health Disaster and Emergency Response Operations Plan. Tehran: Azarbarzin; 2015(Persian)

22. Schoenthal L. A case study in the identification of critical factors leading to successful implementation of the hospital incident command system. NAVAL POSTGRADUATE SCHOOL MONTEREY CA; 2015 Jun.

23. Yazdi-Feyzabadi V, Emami M, Mehrolhassani MH. Health information system in primary health care: the challenges and barriers from local providers' perspective of an area in Iran. International journal of preventive medicine. 2015;6.

24. Ministry of Health and Medical Education (MOHME). I.R. Iran National Response Framework (NRF). 2019 (Persian).

25. Bahrami P, Ardalan A, Nejati A, Ostadtaghizadeh A, Developing the evaluation system for "Incident commanding system"(ICS) in response to disasters and emergencies. Doctorate Thesis in Tehran university of medical sciences. 2019. 
26. Xu M, Li SX. Analysis of good practice of public health Emergency Operations Centers. Asian Pacific journal of tropical medicine. 2015 Aug 1;8(8):677-82.

27. Andrew SA, Kendra JM. An adaptive governance approach to disaster-related behavioural health services. Disasters. 2012 Jul;36(3):514-32.

28. Briggs SM. Regional interoperability: making systems connect in complex disasters. Journal of Trauma and Acute Care Surgery. 2009 Aug 1;67(2):S88-90.

29. Al-Shareef AS, Alsulimani LK, Bojan HM, Masri TM, Grimes JO, Molloy MS, Ciottone GR. Evaluation of hospitals' disaster preparedness plans in the Holy City of Makkah (Mecca): a cross-sectional observation study. Prehospital and disaster medicine. 2017 Feb 1;32(1):33.

30. Djalali A, Della Corte F, Segond F, Metzger MH, Gabilly L, Grieger F, Larrucea X, Violi C, Lopez C, ArnodPrin P, Ingrassia PL. TIER competency-based training course for the first receivers of CBRN casualties: a European perspective. European journal of emergency medicine. 2017 Oct 1;24(5):3716.

31. Morse Disaster Preparedness. In: Gorin SS, Arnold J. Health promotion in practice. John Wiley \& Sons; 2006 Apr 7. P. 445-459

32. Burkle FM, Hsu EB, Loehr M, Christian MD, Markenson D, Rubinson L, Archer FL. Definition and functions of health unified command and emergency operations centers for large-scale bioevent disasters within the existing ICS. Disaster medicine and public health preparedness. 2007 Nov 1;1(2):135-41.

33. Adams EH, Scanlon E, Callahan III JJ, Carney MT. Utilization of an incident command system for a public health threat: West Nile virus in Nassau County, New York, 2008. Journal of Public Health Management and Practice. 2010 Jul 1;16(4):309-15.

34. Ukai T. New type of preventable death. Prehospital and disaster medicine. 2005 Jun;20(3):202-.

35. Shams I, Yarmohamadian MH, Atighechian G, Haghshenas A. Hospital Preparedness for Isfahan University of Medical Sciences to establish Hospital Incident Command System. Journal of Rescue and Relief. 2010; 2(1). http://eprints.bpums.ac.ir/id/eprint/5267 . (Persian)

36. Autrey P, Moss J. High-reliability teams and situation awareness: implementing a hospital emergency incident command system. JONA: The Journal of Nursing Administration. 2006 Feb 1;36(2):67-72.

37. O'Neill PA. The ABC's of disaster response. Scandinavian journal of surgery. 2005 Dec;94(4):259-66.

38. Aitken P, Leggat PA, Robertson AG, Harley H, Speare R, Leclercq MG. Leadership and use of standards by Australian disaster medical assistance teams: results of a national survey of team members. Prehospital and disaster medicine. 2012 Apr 1;27(2):142.

39. Buck DA, Trainor JE, Aguirre BE. A critical evaluation of the incident command system and NIMS. Journal of Homeland Security and Emergency Management. 2006 Sep 13;3(3).

40. Born CT, Briggs SM, Ciraulo DL, Frykberg ER, Hammond JS, Hirshberg A, Lhowe DW, O'Neill PA. Disasters and mass casualties: I. General principles of response and management. JAAOS-Journal of the American Academy of Orthopaedic Surgeons. 2007 Jul 1;15(7):388-96. 
41. Born CT, Monchik KO, Hayda RA, Bosse MJ, Pollak AN. Essentials of disaster management: the role of the orthopaedic surgeon. Instr Course Lect. 2011 Jan 1;60:3-14.

42. Fares S, Femino M, Sayah A, Weiner DL, Yim ES, Douthwright S, Molloy MS, Irfan FB, Karkoukli MA, Lipton R, Burstein JL. Health care system hazard vulnerability analysis: an assessment of all public hospitals in Abu Dhabi. Disasters. 2014 Apr;38(2):420-33.

43. Londorf D. Hospital application of the incident management system. Prehospital and Disaster Medicine. 1995 Sep;10(3):184-8.

44. Hoffner P, Keck B, Hemphill R, Wells N. Integrating physician response into an academic medical center emergency operations response plan. Journal of Emergency Nursing. 2009 Jul 1;35(4):343-7.

45. Yarmohammadian MH, Atighechian G, Shams L, Haghshenas A. Are hospitals ready to response to disasters? Challenges, opportunities and strategies of Hospital Emergency Incident Command System (HEICS). Journal of research in medical sciences: the official journal of Isfahan University of Medical Sciences. 2011 Aug;16(8):1070.

46. Kanter RK. Critical Care in Public Health Emergencies. Pediatric Critical Care: Elsevier Inc.; 2011. p. $190-5$.

\section{Figures}

\section{Provincial Medical University}

\section{District Health Network}

\section{District Health Center}

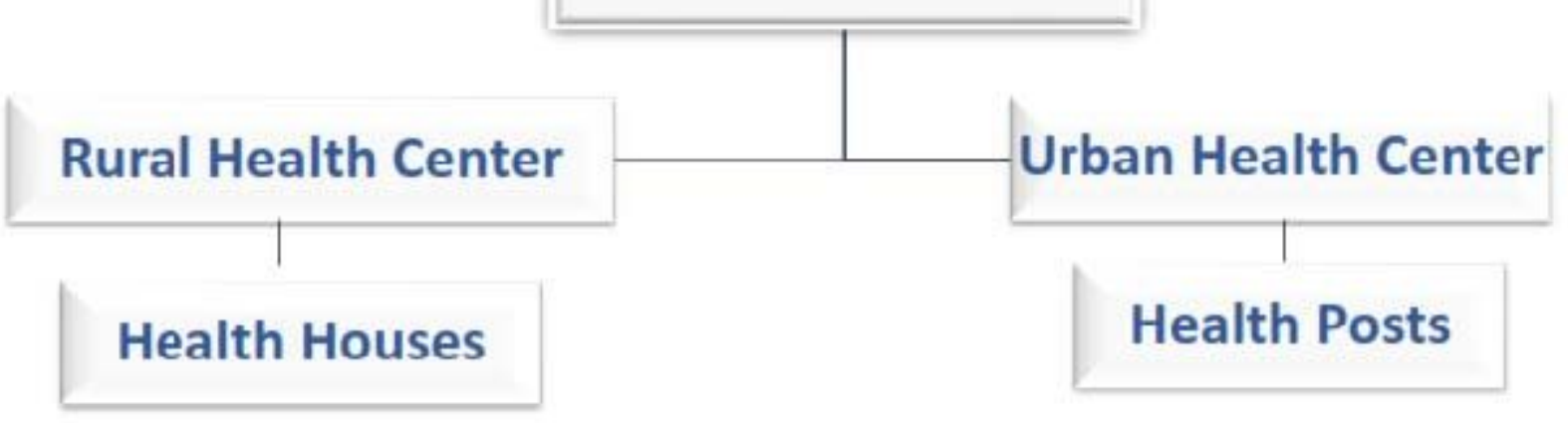

\section{Figure 1}

Public Healthcare system structure in Iran 


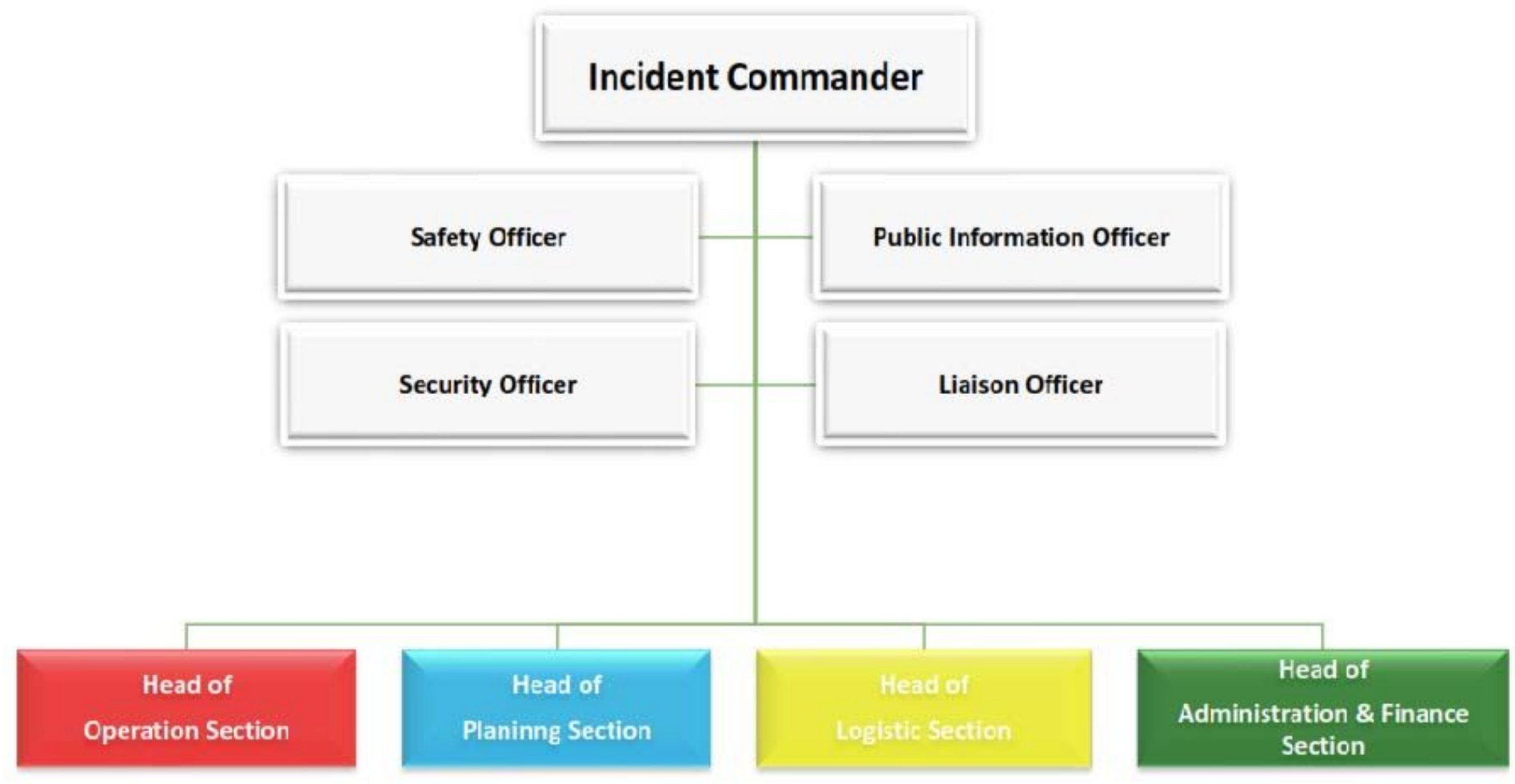

Figure 2

Healthcare Incident Command System in Iran 